
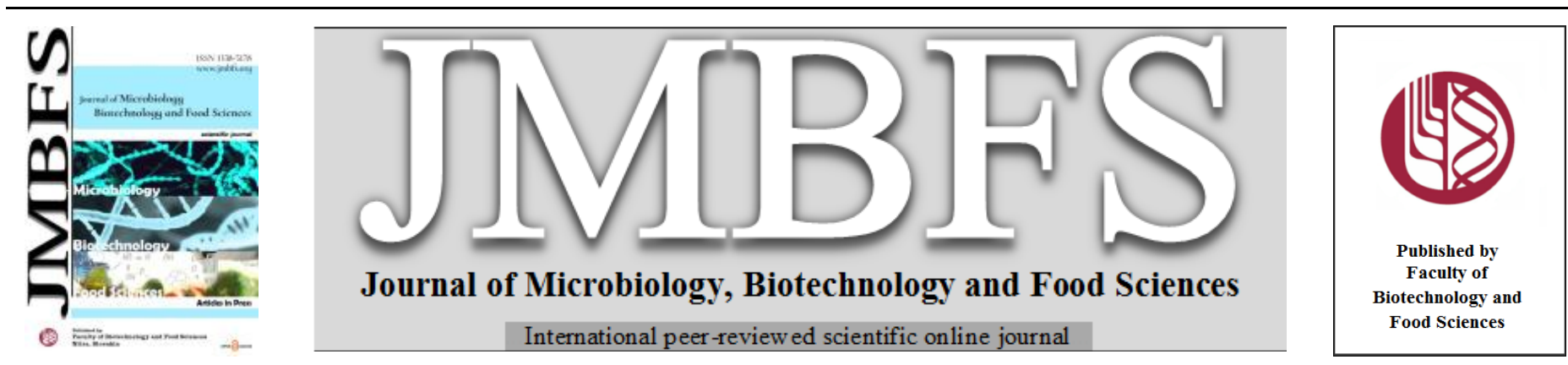

\title{
SYNTHESIS OF CARBONYL COMPOUNDS FROM SACCHAROMYCES CEREVISIAE STRAINS IN CABERNET SAUVIGNON WINES
}

\author{
Tatyana Yoncheva*1, Hristo Spasov², Georgi Kostov ${ }^{2}$ \\ Address(es): \\ ${ }^{1}$ Institute of Viticulture and Enology, Department of Vine Selection, Enology and Chemistry, 1 "Kala tepe" str., 5800 Pleven, Bulgaria. \\ ${ }^{2}$ University of Food Technologies, Department of Technology of Wine and Brewing, 26 "Maritsa" blvd., 4002 Plovdiv, Bulgaria.
}

*Corresponding author: $\mathrm{t}$ ion@abv.bg

https://doi.org/10.15414/jmbfs.4417

\section{ARTICLE INFO}

Received 1.3. 2021

Revised 16. 7. 2021

Accepted 5. 8. 2021

Published 1. 12. 2021

Regular article OPEN $\partial_{\text {ACCESS }}$

\section{ABSTRACT}

The ability of two Saccharomyces cerevisiae strains (Bordeaux, 8-11) to produce carbonyl compounds under different conditions of the alcoholic fermentation was investigated. The impact of the temperature and the inoculum yeast culture ratio on the synthesis of total aldehydes during the process was traced. A more pronounced effect of the temperature was observed. At the beginning of the fermentation, the total aldehydes rate increased rapidly and reached a maximum during the exponential phase of the yeast cells development (day $5^{\text {th }}$ ), thereafter their amount began to go down. The strain Saccharomyces cerevisiae Bordeaux synthesized the most total aldehydes at a temperature of $24^{\circ} \mathrm{C}$, while Saccharomyces cerevisiae 8-11 - at $28^{\circ} \mathrm{C}$. Acetaldehyde, acetone and 2-butanone were identified in the experimental wines by gas chromatographic analysis. During the fermentation at a temperature of $20^{\circ} \mathrm{C}$ and $24^{\circ} \mathrm{C}$, Saccharomyces cerevisiae Bordeaux produced more acetaldehyde, acetone and 2-butanone compared to $8-11$. At $28^{\circ} \mathrm{C} \mathrm{Saccharomyces}$ cerevisiae 8-11 produced more acetaldehyde and 2-butanone, 33.3\% and 15\% respectively, and 30\% less acetone than Saccharomyces cerevisiae Bordeaux. The total aldehydes rate in the experimental samples did not have a negative effect on their aromatic and taste qualities.

Keywords: yeast, Cabernet Sauvignon, alcoholic fermentation, wine, aldehydes, sensory characteristic

\section{INTRODUCTION}

The chemical composition of wine has been diverse, including numorous substances and compounds, some of which passed from the grapes, while others were formed in the process of the alcoholic fermentation, malolactic fermentation and storage.

From the group of the carbonyl compounds in the wine there were aldehydes (fatty, aromatic and furan) and ketones. Only traces, mainly of acetaldehyde, propionic and isobutyric aldehydes were found in grapes (Chobanova, 2012). During the alcoholic fermentation, the yeast produced over 20 aldehydes from different precursors - amino acids, the respective alcohols, sugars. Most of them were formed as a result of the yeast metabolism, under the action of the alcohol dehydrogenase enzyme and the primary alcohol oxidation to aldehyde. There had been other mechanisms too - by enzymatic oxidation of alcohols by the yeast, by non-enzymatic oxidation of primary alcohols under the action of oxygen from the air, by oxidative deamination of amino acids and decarboxylation of keto acids, with the participation of quinones (Bambalov, 1981; Romano et al., 1994; Jackowetz et al., 2011 b; Chobanova, 2012; Herzan et al., 2020).

Their total amount varied from 10 to $200 \mathrm{mg} / \mathrm{L}, 90 \%$ of which had been acetaldehyde. It was the main volatile carbonyl component in wine that might be produced biologically (from yeast) or chemically (by oxidation). Of the acetaldehyde contained in the wine, only a small part originated from sugars. The rest had other paths of origin. It had been an intermediate product of alcoholic fermentation and was formed after decarboxylation of the pyruvic acid and before the ethanol synthesis. Other pathways of origin had been the self-oxidation of phenolic compounds to quinones with the evolution of $\mathrm{O}_{2}$, which oxidized the ethyl alcohol to acetaldehyde, and the oxidative decarboxylation of valine under appropriate conditions (Romano et al., 1994; Chobanova, 2012; Mina and Tsaltas, 2017; Lago and Welke, 2019; Filimon et al., 2021).

The acetaldehyde rate produced by the yeast changed during the alcoholic fermentation. At the onset of the process, its amount gradually increased, thereafter equilibrium occurred between its synthesis and its reduction to ethyl alcohol. Its concentration reached a maximum during the exponential phase of yeast cell development. Upon fermentation of $40-50 \%$ of the sugars its quantity began to drop down (Bambalov, 1981; Jackowetz et al., 2011 b; Orduña, 2014;
Rosca et al., 2016; Herzan et al., 2020). That was due to its participation in the condensation processes with phenols or nitrogenous substances in the medium, its reduction to ethanol, its interaction with $\mathrm{SO}_{2}$ and formation of a permanent aldehyde-bisulfite compound, interaction with the fermentation by-products (Frivik and Ebeler, 2003; Swiegers et al., 2005; Bueno et al., 2018; Ferreira et al., 2018; Lago and Welke, 2019).

The acetaldehyde concentration also affected the course of fermentation during the stationary phase of yeast development, when the alcohol content increased significantly. During this period, the supplement of acetaldehyde in the medium in high concentrations inhibited the process, while in moderate and low doses stimulated it. The acetaldehyde content could also be modulated by modifying the alcohol dehydrogenase catalytic reaction (Roustan and Sablayrolles, 2002). While maintaining its viability yeast could reduce the amount of acetaldehyde during the last stages of fermentation and in prolonged contact with wine (Jackowetz et al., 2011 a).

Ketones in wine were also formed during the alcoholic fermentation by enzymatic oxidation of alcohols. They oxidized significantly more difficult, the reactions with $\mathrm{SO}_{2}$ were very slow, binding about $65-85 \%$ of the keto compounds in wine. Their total amount could reach $40-60 \mathrm{mg} / \mathrm{L}$ mainly acetoin, diacetyl and $\gamma$-butyrolactone (Rosca et al., 2016; Mina and Tsaltas, 2017). The concentration of acetone was 1-3 mg/L (Chobanova, 2012).

The carbonyl compounds content in wines had been influenced by a number of technological factors such as degree of ripeness and composition of grapes, $\mathrm{SO}_{2}$ content, the species and strain of yeast, fermentation conditions (temperature, aeration), $\mathrm{pH}$ of the medium, contact with air, heat treatment during vinification or storage (Romano et al., 1994; Jackowetz et al., 2011 b; Chobanova, 2012; Rosca et al., 2016; Lago et al., 2017; Bueno et al., 2018; Herzan et al., 2020; Licek et al., 2020; Filimon et al., 2021). Yeast usually reduced acetaldehyde to ethanol, but under conditions of increased aeration and oxygen content in the medium, they could also perform the reverse reaction by oxidation.

The metabolic kinetics of acetaldehyde synthesis from Saccharomyces and nonSaccharomyces strains had been similar, however a significant variation in its amount was observed. Some non-Saccharomyces strains produced much less $(C$. vini, $H$. anomala, H. uvarum, M. pulcherrima) or much higher (C. stellata, $Z$. bailli, S. pombe) amounts compared to Saccharomyces strains (Romano et al., 
1994; Li and Orduña, 2017). According to research of Liu at al. (2016) more aldehydes were produced in inoculated fermented wines than in spontaneously fermented wines which was mainly associated with decanal and benzeneacetaldehyde.

The acetaldehyde producing had been strongly affected by the fermentation temperature. According to most studies, it was enhanced when the temperature rised. Higher acetaldehyde rate was formed at higher fermentation temperature or $\mathrm{pH}$ (Byrne and Howell, 2017). Its content at $30^{\circ} \mathrm{C}$ was significantly higher than at $18^{\circ} \mathrm{C}$ and $24^{\circ} \mathrm{C}$, which might be due to the inhibitory effect of temperature on the activity of alcohol dehydrogenase that catalyzed the conversion of acetaldehyde to ethanol (Romano et al., 1994). According to Jackowetz et al. (2011 b), however, lower fermentation temperatures were associated with the formation of higher concentrations of acetaladehyde, due to the lower degree of its conversion during the second phase of fermentation and the higher content of residual sugars.

Wines obtained without sulphitation of grape must contained small amounts of aldehydes. In the presence of $\mathrm{SO}_{2}$ in the fermentation medium, aldehydes bound to it and accumulated in the wine. (Bambalov, 1981; Romano et al., 1994; Chobanova, 2012; Jackowetz et al., 2011 a; Jackowetz et al., 2011 b; Li and Orduña, 2017; Lago and Welke, 2019). The addition of $\mathrm{SO}_{2}$ to the grapes must increased production of acetaldehyde by the yeast. Acetaldehyde formation was a way of protecting yeast from the antiseptic effects of $\mathrm{SO}_{2}$ (Herzan et al., 2020).

According to some studies, the amount of aldehydes in red wines was higher than in white wines, because after oxidation, phenolic compounds served as catalysts for the formation of acetaldehyde (Chobanova, 2012). According to others, however, during malolactic fermentation, malolactic bacteria significantly reduced its amount by metabolizing acetaldehyde to ethanol. Terefore, its concentration in red wines was less than in white ones (Jackowetz et al., 2011 a; Orduña, 2014; Herzan et al., 2020).

Carbonyl compounds had been one of the most reactive groups of wine substances. Their representatives, as well as the products of the reactions in which they participate, affected the wine composition and its organoleptic qualities (Romano et al., 1994; Chobanova, 2012; Liu at al., 2016). Aldehydes and ketones were easily volatile substances with a specific flavor that determined their great influence for the wine aroma and bouquet. Fatty and aromatic aldehydes had a strong fruity aroma. Acetaldehyde, as the main aldehyde in wine, in low ratios had the smell of a green apple, freshly cut grass or walnuts but at a ratio over $100 \mathrm{mg} / \mathrm{L}$ gave an oxidized tinge (Jackowetz et al., 2011 b; Chobanova, 2012; Orduña, 2014; Byrne and Howell, 2017; Filimon et al., 2021). Concetration of up to $100 \mathrm{mg} / \mathrm{L}$ of acetaldehyde and $1-4 \mathrm{mg} / \mathrm{L}$ of diacetyl could be described as desirable and contributing to the complexity of wine aroma (Mina and Tsaltas, 2017). Ketones also had a specific smell and could give the wine both pleasant and negative nuances. In high doses they negatively affected the aroma of wine, associated with oxidation (Chobanova, 2012; Rosca et al., 2016).

The purpose of the present research was to study the synthesis of aldehydes during the alcoholic fermentation, the carbonyl compounds content in Cabernet Sauvignon wines and their significance for wine sensory characteristics.

\section{MATERIAL AND METHODS}

\section{Vinification}

The investigation was carried out at the Institute of Viticulture and Enology (IVE), Pleven, Bulgaria. Grapes of Cabernet Sauvignon variety, cultivated at the experimental vineyards of the IVE, was used for the trials. The grapes were harvested at optimal technological maturity and processed according to the classic red dry winemaking technology under the conditions of microvinification (Yankov, 1992).

\section{Alcoholic fermentation}

The process occurred under the following conditions:

- $4.0 \mathrm{~kg}$ of grape pomace, sulfated with $50 \mathrm{mg} / \mathrm{kg} \mathrm{SO}_{2}$, with sugars content $23.10 \%$ and titratable acids $6.15 \mathrm{~g} / \mathrm{L}$;

- Inoculum - 48-hour active yeast culture of the strains Saccharomyces cerevisiae Bordeaux and Saccharomyces cerevisiae 8-11, in quantity of 2\%, 3\%, $4 \%$

- Fermentation temperature $-20^{\circ} \mathrm{C}, 24^{\circ} \mathrm{C}, 28^{\circ} \mathrm{C}$

- Daily control of the process by monitoring the change in dry matter, measured with an Abbe refractometer to a constant value.

The dynamics of the total aldehydes during the fermentation was monitored on day $1^{\text {st }}$, on day $5^{\text {th }}$ (rapid phase), on day $10^{\text {th }}$ (quiet phase) and

after the malolactic fermentation. Their quantity was defined by the bisulphite method (Ivanov et al., 1979). The course of spontaneous malolactic fermentation was qualitatively monitored by paper chromatography for organic acids (Kramer, 1961).

\section{Neural networks}

The experimental results from all variants were modeled through neural networks of the Statistica 8 software package using a second order quasi-Newton algorithm describing the influence of time, fermentation temperature and inoculum yeast culture on aldehydes synthesis. The results were presented in the form of surfaces that described the experimental data with high precision (Chen et al., 2006, Nicoletti et al., 2009).

\section{Chemical composition}

All experimental wines were analyzed for the ratio of alcohol, vol. \% (distillation method, Gibertini distillation apparatus with densitometer); sugars, g/L (Schoor method); total aldehydes $\mathrm{mg} / \mathrm{L}$ (bisulphite method) and $\mathrm{pH}$ ( $\mathrm{pH}$-meter) (Ivanov et al., 1979).

The content of carbonyl compounds (acetaldehyde, acetone, 2-butanone) in the experimental variants were identified and qualitatively determined by gas chromatographic analysis made with GC 8000 Top Series (Yoncheva $\boldsymbol{e t}$ al., 2019). The volatile components were extracted from the wine by the "headspace" method (Hrivňak et al., 2004; Kružlicova et al., 2006). Based on the peak area, the ratio difference in the component content between the different variants was calculated. The samples, obtained at $20^{\circ} \mathrm{C}$ and $2 \%$, were considered to be the standard (100\%). For comparing both strains, Saccharomyces cerevisiae Bordeaux strain was assumed for standard (100\%)

\section{Organoleptic profile}

The sensory characteristics of the wines were evaluated by a 100 -score system (Tsvetanov, 2001) by a 5-member tasting commission from the University of Food Technologies in Plovdiv, Bulgaria. All members of the tasting panel were experts - oenologists with long practice and experience in sensory analysis of wines. Mathematical modeling of the organoleptic analysis results was performed, presented by response surfaces.

\section{RESULTS AND DISCUSSION}

\section{Alcoholic fermentation}

When monitoring the course of the alcoholic fermentation, a similarity in the dry matter change was observed under the different process conditions. The studied strains showed high fermentation activity, as the intensity with which the fermentation began and the time for its completion were in correlation with the temperature and the quantity of inoculum yeast culture. At $20^{\circ} \mathrm{C}$ the fermentation started and proceeded more slowly. The studied strains demonstrated the highest activity at $28^{\circ} \mathrm{C}$. With the increase of the inoculum yeast amount within one temperature range, fermentation started and ended earlier.

Figure 1 showed the change of dry matter during the alcoholic fermentation, taking place under the conditions of 3\% active yeast culture inoculum and temperature $20^{\circ} \mathrm{C}, 24^{\circ} \mathrm{C}$ and $28^{\circ} \mathrm{C}$ with the studied yeast strains. The results from following up the process in the other experimental variants were similar.

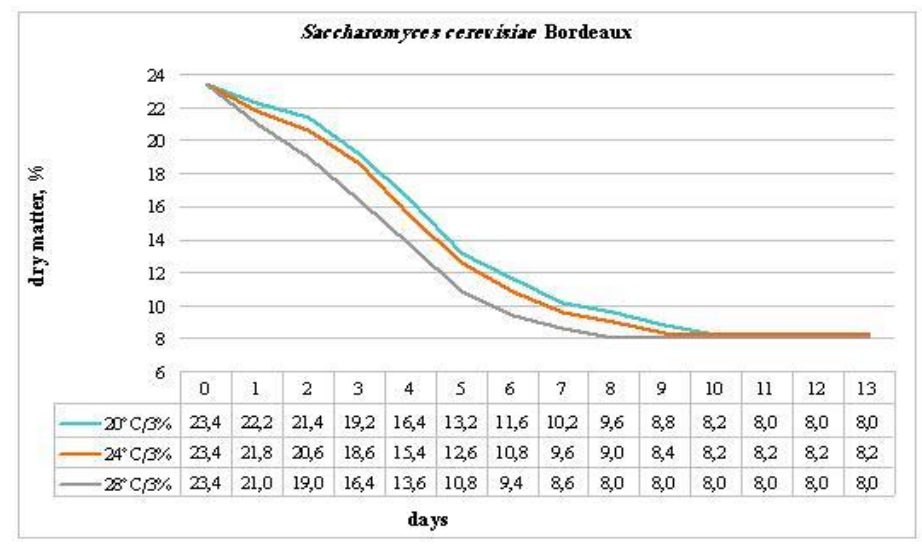




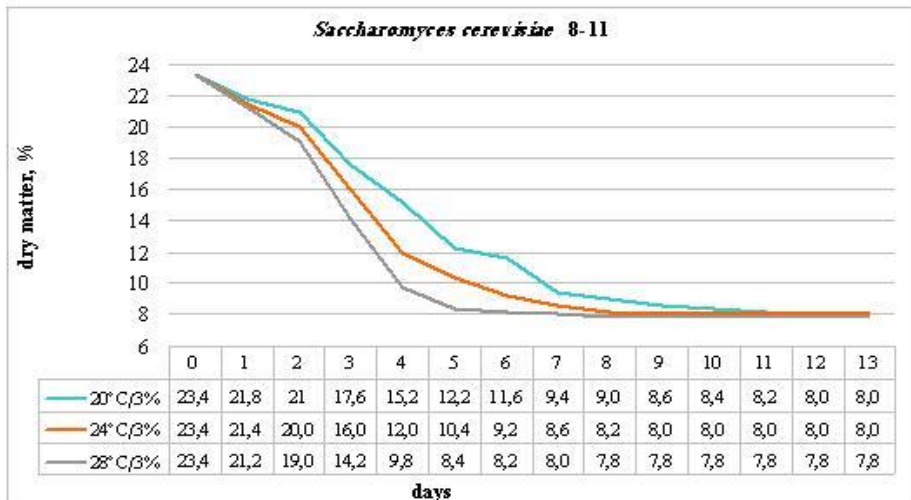

Figure 1 Change of dry matter during the alcoholic fermentation with the studied strains Saccharomyces cerevisiae

Neural networks and total aldehydes accumulation during the alcoholic fermentation

During the fermentation, the synthesis of total aldehydes from the strains was monitored, depending on the change of the fermentation parameters, temperature and amount of inoculum yeast culture. Figure 2 and figure 3 showed the dynamics of accumulation of their total amount during the process (day $1^{\text {st }}, 5^{\text {th }}$ $10^{\text {th }}, 20^{\text {th }}$ ). Neural networks were drawn up for all variants, modeling the processes and characterized by high accuracy of description of the experimental data. They demonstrated a stronger effect of the temperature than the amount of inoculum yeast culture.

The results obtained, describing the total aldehydes change during the alcoholic fermentation, were similar to those found by other authors (Bambalov, 1981; Swiegers et al., 2005; Orduña, 2014). At the onset of the process, their rate increased rapidly and reached a peak during the exponential phase of yeast cell development $\left(5^{\text {th }}\right.$ day $)$. After the fermentation of most of the sugars in the middle of the process, their rate began to decrease (day $10^{\text {th }}$ ). That was due to their participation (mainly acetaldehyde) in the condensation processes or its reduction to ethanol and interaction with $\mathrm{SO}_{2}$.
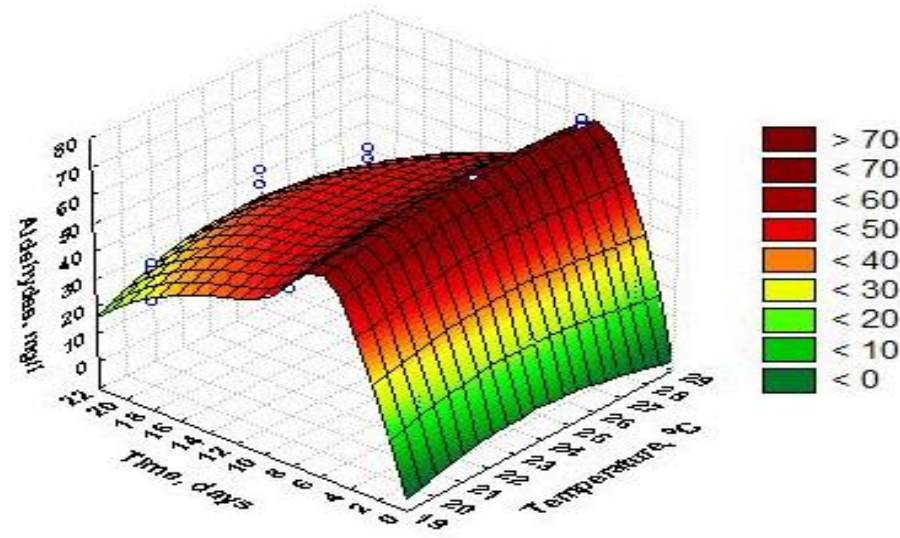

a)

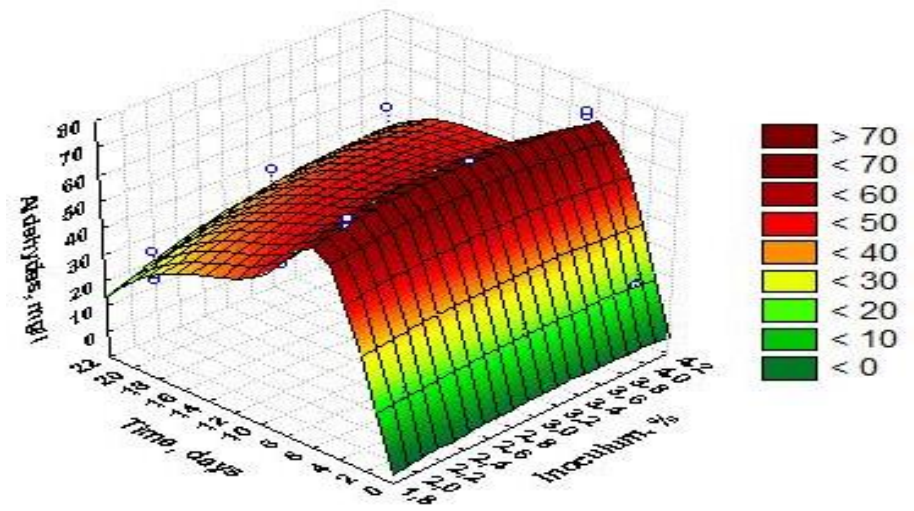

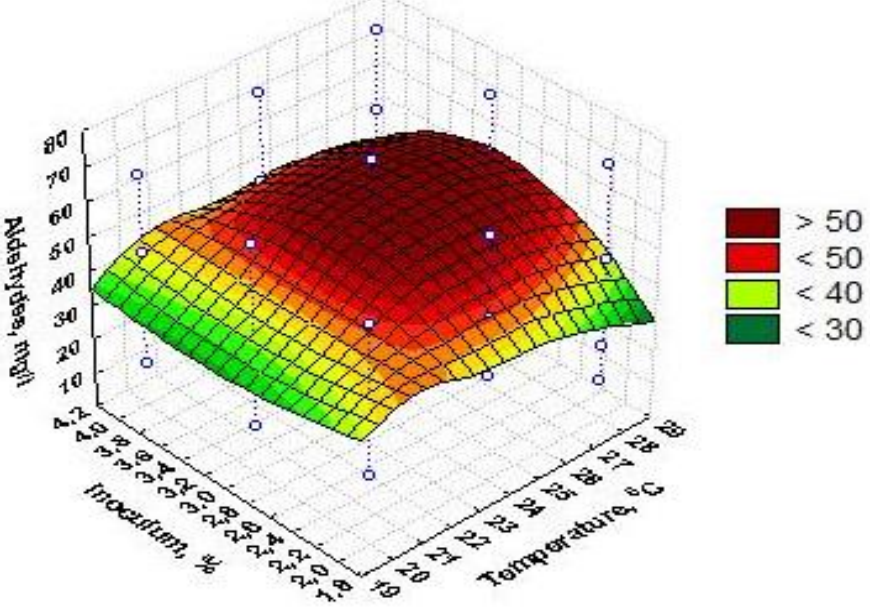

c)

Figure 2 Change in total aldehydes during the alcoholic fermentation with the strain Bordeaux

a) influence of temperature

b) influence of inoculum yeast culture amount

c) influence of temperature and inoculum yeast culture amount

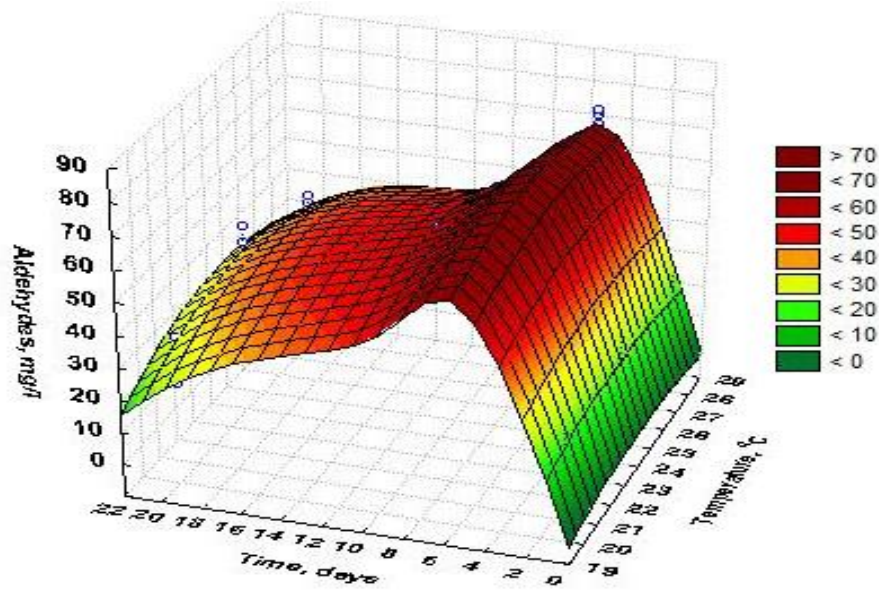

a)

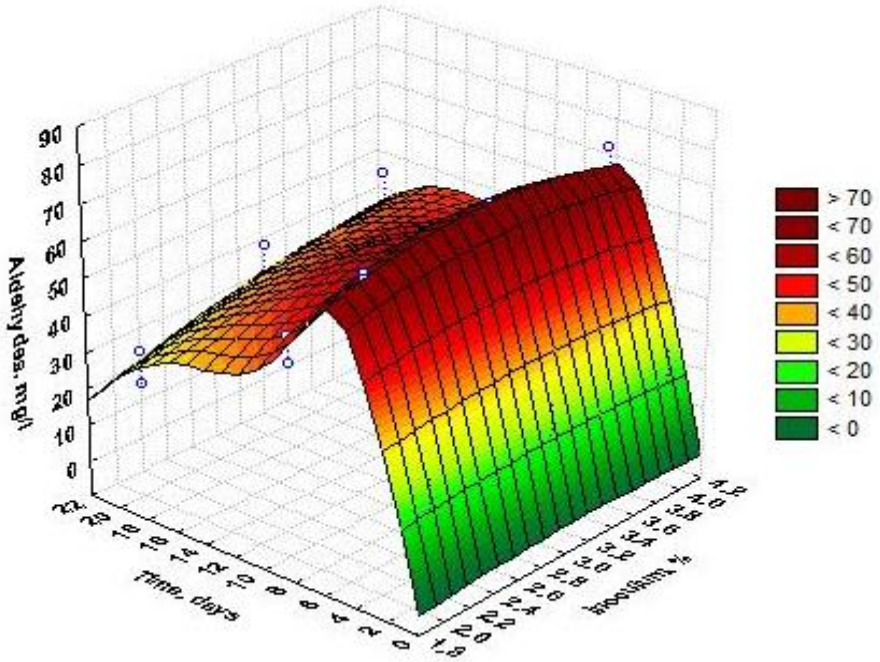

b)

b) 


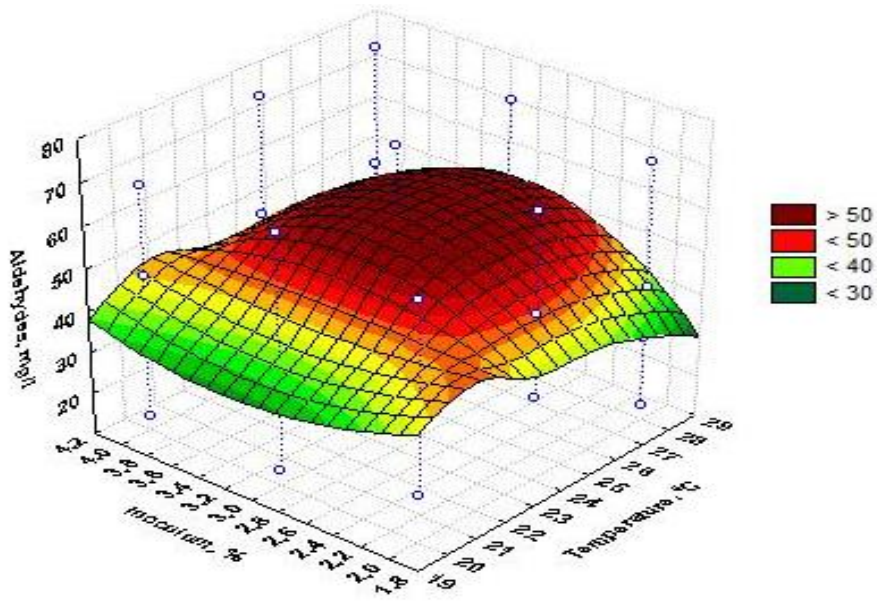

c)

Figure 3 Change in total aldehydes during the alcoholic fermentation with the strain 8-11

a) influence of temperature

b) influence of inoculum yeast culture amount

c) influence of temperature and inoculum yeast culture amount

In the conditions of this experiment there was no clear general trend of the studied yeast to synthesize the maximum amount at a certain temperature. The strains showed different ability to produce aldehydes depending on the conditions. No correlation between the temperature and the concentration of the tested metabolite was observed in the samples fermented with the strain Saccharomyces cerevisiae Bordeaux. Most total aldehydes were produced at $24^{\circ} \mathrm{C}$ - from 78.68 to $83.20 \mathrm{mg} / \mathrm{L}$ (day $5^{\text {th }}$ ) and from 48.95 to $56.88 \mathrm{mg} / \mathrm{L}$ (day $10^{\text {th }}$ ), respectively. Saccharomyces cerevisiae $8-11$ produced the highest amount of aldehydes when the fermentation occurred at $28^{\circ} \mathrm{C}$ - from 78.00 to $85.60 \mathrm{mg} / \mathrm{L}$ (day $5^{\text {th }}$ ) and from 55.36 to $62.72 \mathrm{mg} / \mathrm{L}$ (day $10^{\text {th }}$ ). With both strains within one temperature range when increasing the amount of yeast culture the rate of total aldehydes went up.

The results modeled by means of the neural networks confirmed that trend. The presented surfaces described their rate in the samples during the rapid phase under the individual and overall impact of the studied fermentation factors (Fig $2,3)$. In the strain Saccharomyces cerevisiae Bordeaux, the peak was observed in the variant $24^{\circ} \mathrm{C} / 4 \%(83.20 \mathrm{mg} / \mathrm{L})$, and in the strain $8-11$ in $28^{\circ} \mathrm{C} / 4 \%(85.60$ $\mathrm{mg} / \mathrm{L}$ ). The minimum for both strains was at $20^{\circ} \mathrm{C} / 2 \%-66.85 \mathrm{mg} / \mathrm{L}$ (Bordeaux) and $68.20 \mathrm{mg} / \mathrm{L}(8-11)$, respectively. The stronger effect of temperature on the fermentation process and the wine components was more pronounced in 8-11 than in Bordeaux.

\section{Chemical composition}

The chemical composition of the obtained wines, after the alcoholic and malolactic fermentation, in terms of the alcohol, sugars and total aldehydes content, was presented in table 1 . No significant contrast was found in the total aldehydes concentration produced by both strains in the wines. In the samples of the Saccharomyces cerevisiae Bordeaux their amount varied from 24.46 to 46.70 $\mathrm{mg} / \mathrm{L}$, and in the samples of Saccharomyces cerevisiae 8-11 - from 22.24 to $53.38 \mathrm{mg} / \mathrm{L}$. The strain Saccharomyces cerevisiae Bordeaux synthesized the most at a temperature of $24^{\circ} \mathrm{C}$, while Saccharomyces cerevisiae 8-11 strain at $28^{\circ} \mathrm{C}$.

Table 1 Chemical compositions and total aldehydes concentration in the experimental wines obtained with the studied strains Saccharomyces cerevisiae

\begin{tabular}{|c|c|c|c|c|c|c|c|c|c|}
\hline \multirow[b]{2}{*}{ Indicators } & \multicolumn{3}{|c|}{$20^{\circ} \mathrm{C}$} & \multicolumn{3}{|c|}{$24^{\circ} \mathrm{C}$} & \multicolumn{3}{|c|}{$28^{\circ} \mathrm{C}$} \\
\hline & $2 \%$ & $3 \%$ & $4 \%$ & $2 \%$ & $3 \%$ & $4 \%$ & $2 \%$ & $3 \%$ & $4 \%$ \\
\hline & \multicolumn{9}{|c|}{ Saccharomyces cerevisiae Bordeaux } \\
\hline Alcohol, vol. \% & 12.75 & 12.95 & 12.72 & 12.84 & 12.72 & 12.81 & 12.74 & 12.76 & 12.80 \\
\hline Sugar, g/L & 2.35 & 1.81 & 2.18 & 1.98 & 2.01 & 2.22 & 2.18 & 2.35 & 2.08 \\
\hline Total aldehydes, mg/L & 24.46 & 28.91 & 37.81 & 40.03 & 44.48 & 46.70 & 31.14 & 35.58 & 37.81 \\
\hline $\mathrm{pH}$ & 3.24 & 3.16 & 3.19 & 3.17 & 3.16 & 3.16 & 3.15 & 3.12 & 3.15 \\
\hline \multirow[t]{2}{*}{ Tasting score } & 82.62 & 80.37 & 83.37 & 82.75 & 87.12 & 78.87 & 79.62 & 81.37 & 86.75 \\
\hline & \multicolumn{9}{|c|}{ Saccharomyces cerevisiae 8-11 } \\
\hline Alcohol, vol. \% & 12.74 & 12.79 & 12.80 & 12.72 & 12.74 & 12.87 & 12.78 & 12.83 & 12.87 \\
\hline Sugar, g/L & 1.74 & 2.01 & 1.48 & 1.48 & 1.10 & 1.04 & 1.67 & 1.00 & 1.17 \\
\hline Total aldehydes, mg/L & 22.24 & 28.91 & 31.14 & 28.91 & 31.14 & 31.14 & 44.48 & 48.93 & 53.38 \\
\hline $\mathrm{pH}$ & 3.20 & 3.15 & 3.21 & 3.18 & 3.20 & 3.21 & 3.17 & 3.18 & 3.16 \\
\hline Tasting score & 83.44 & 83.22 & 83.33 & 87.44 & 83.89 & 85.44 & 82.11 & 86.78 & 84.00 \\
\hline
\end{tabular}

The established tendencies were also confirmed by the results of the gas chromatographic analysis (Fig. 4, 5, 6). From the group of carbonyl compounds in the obtained wines, acetaldehyde, acetone and 2-butanone had been identified.

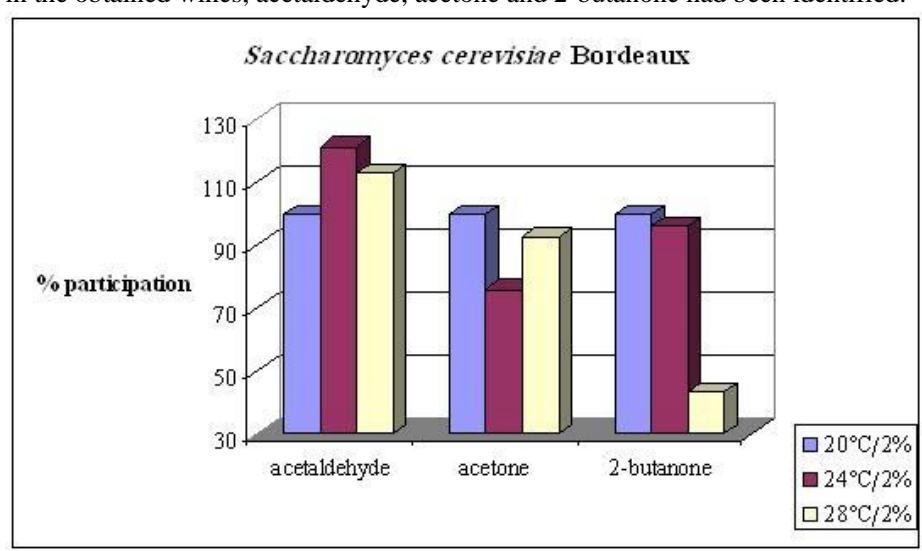

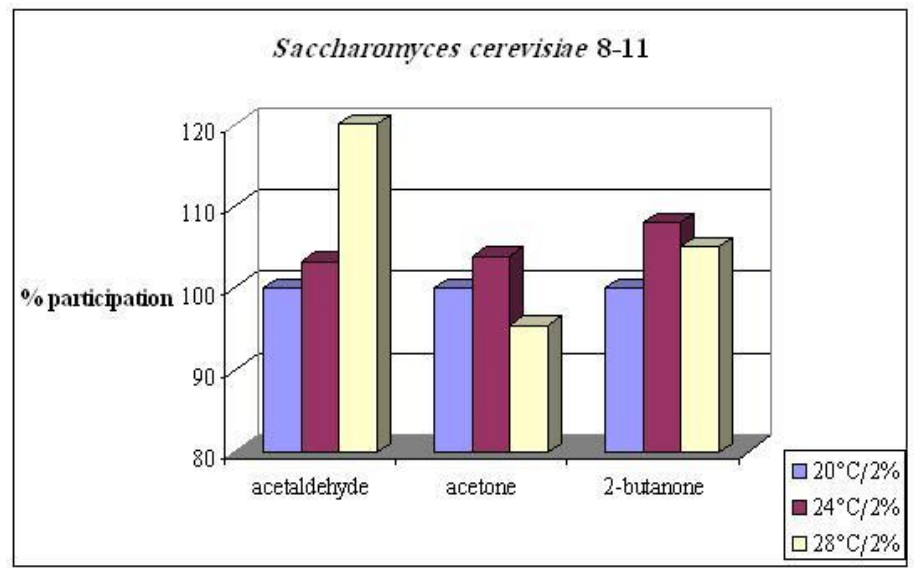

Figure 4 Identified carbonyl compounds (\%) in the experimental wines 


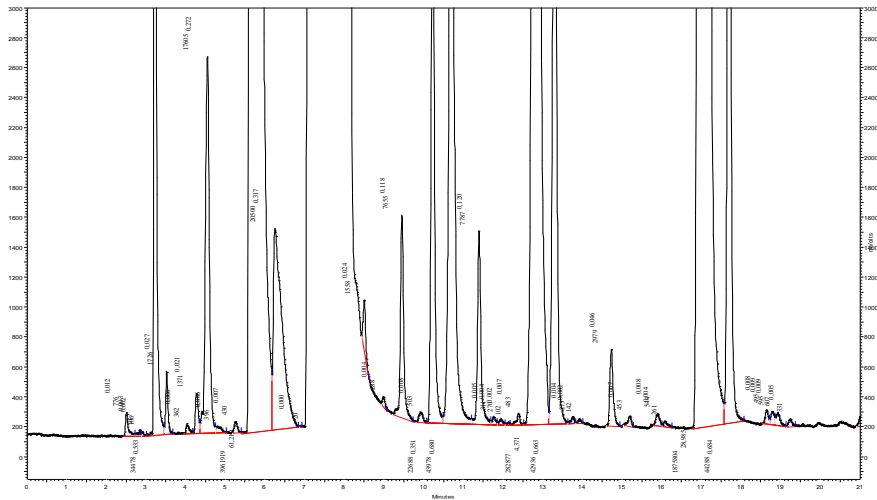

$0-21 \mathrm{~min}$

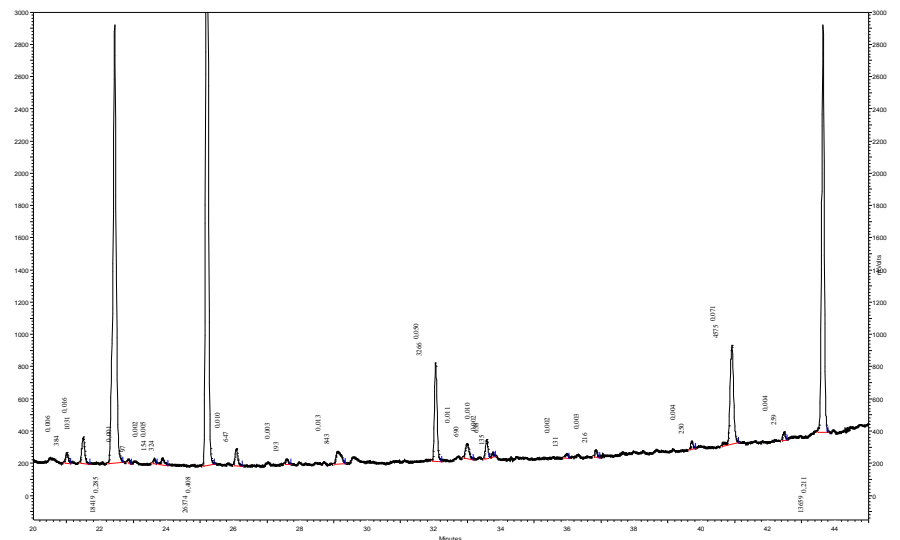

20-45 min

a) Bordeaux strain

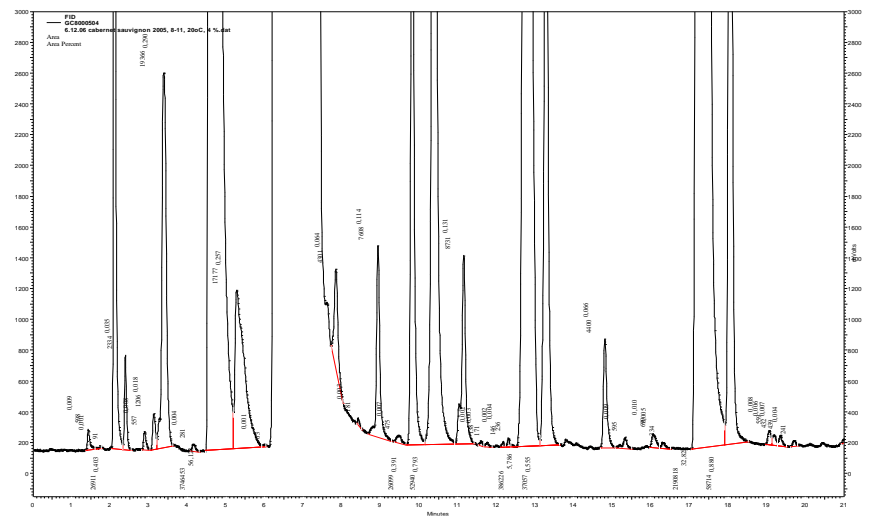

$0-21 \mathrm{~min}$

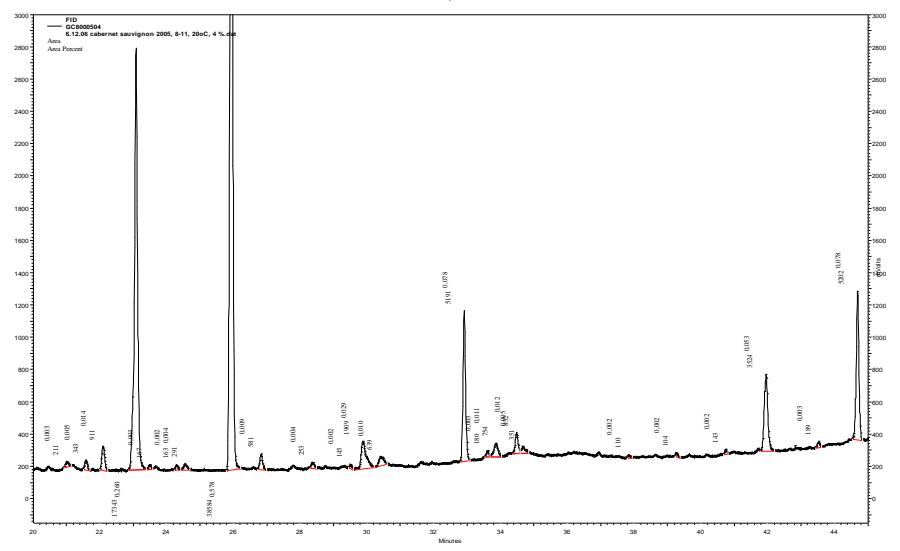

20-45 $\mathrm{min}$

\section{b) 8-11 strain}

Figure 6 Gas chromatographic analysis of the samples, fermented at $20^{\circ} \mathrm{C} / 4 \%$, with the studied strains

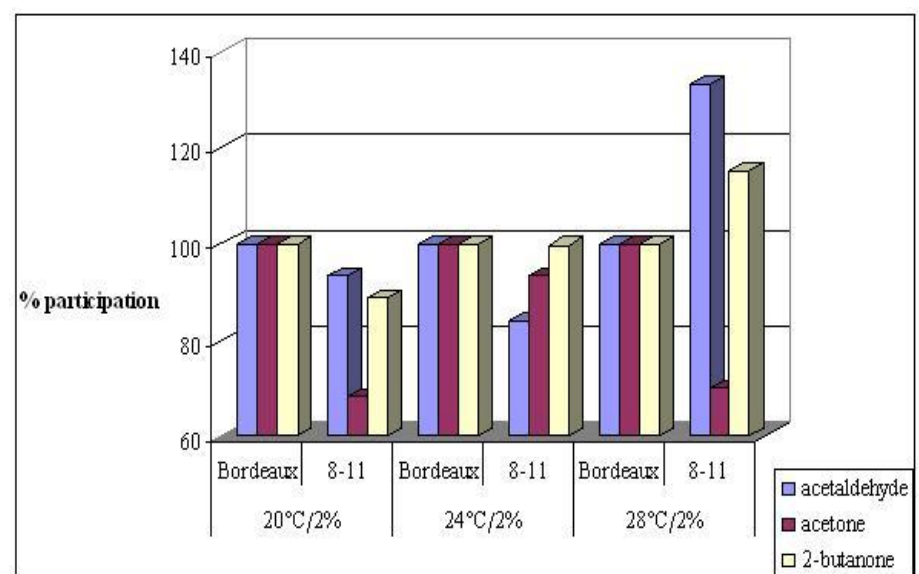

Figure 5 Distribution of the identified carbonyl compounds in the experimental wines

The presented results demonstrated that under the same conditions the strains showed different ability to produce acetaldehyde, acetone and 2-butanone. Bordeaux strain synthesized the most acetaldehyde at $24^{\circ} \mathrm{C}$, and $8-11-$ at $28^{\circ} \mathrm{C}$ Saccharomyces cerevisiae Bordeaux produced more acetone and 2-butanone at $20^{\circ} \mathrm{C}$, and the least acetone at $24^{\circ} \mathrm{C}$ and 2-butanone at $28^{\circ} \mathrm{C}$, respectively. Saccharomyces cerevisiae 8-11 strain synthesized the highest quantity of acetone and 2-butanone at $24^{\circ} \mathrm{C}$ (Fig. 4). During the fermentation at a temperature of $20^{\circ} \mathrm{C}$ and $24^{\circ} \mathrm{C}$, the strain Bordeaux produced more of the studied carbonyl compounds compared to $8-11$ strain. At $28^{\circ} \mathrm{C}, 8-11$ formed more acetaldehyde and 2-butanone, $33.3 \%$ and $15 \%$ respectively, and $30 \%$ less acetone than Bordeaux (Fig. 5).

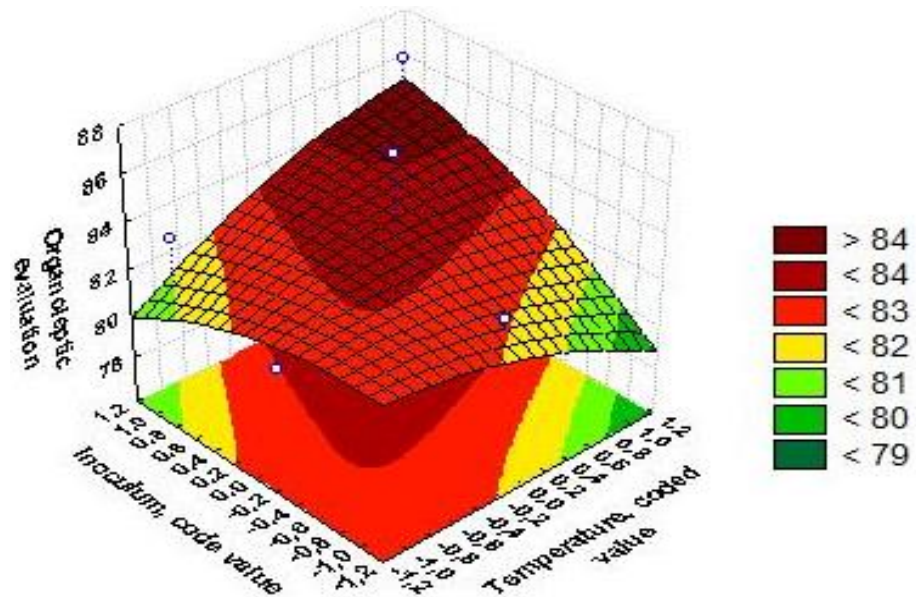

a) Bordeaux strain

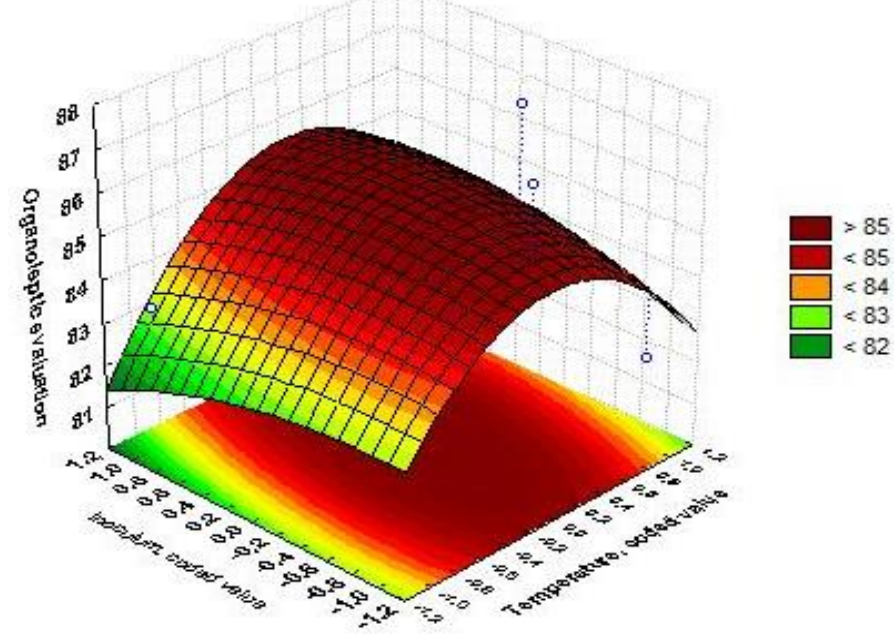

b) 8-11 strain

Figure 7 Response surfaces to describe the tasting evaluations of the experimental wines

The results of the mathematical modeling for the influence of the parameters of the fermentation process on the sensory characteristics of the experimental wines 
confirmed the obtained tasting evaluations (Tab. 1, Fig. 7). The total aldehydes content in the experimental samples did not affect adversely their aromatic and taste qualities. The variant of the strain Bordeaux obtained at $24^{\circ} \mathrm{C} / 3 \%(87.12$ points) containing a higher amount of total aldehydes $(44.48 \mathrm{mg} / \mathrm{L})$ and the variant of $8-11$ strain, obtained at $24^{\circ} \mathrm{C} / 2 \%$ ( 87.44 points), containing a lower amount of aldehydes $(28.91 \mathrm{mg} / \mathrm{L})$ had the best properties and were evaluated with the highest points.

\section{CONCLUSION}

Under the conditions of the experiment, the studied yeasts had different ability to produce total aldehydes and carbonyl compounds. A more pronounced effect of the temperature than the amount of inoculum yeast culture was observed. At the beginning of the fermentation, the aldehydes content increased rapidly and reached a peak during the rapid phase (day $\left.5^{\text {th }}\right)$, thereafter their amount began to decrease (day $10^{\text {th }}, 20^{\text {th }}$ ).

Saccharomyces cerevisiae Bordeaux strain synthesized the most acetaldehyde at a temperature of $24^{\circ} \mathrm{C}$, and Saccharomyces cerevisiae $8-11$ - at $28^{\circ} \mathrm{C}$.

The stronger effect of the temperature on the fermentation process and the wine components was more pronounced in 8-11 strain than in Bordeaux strain.

During the fermentation at $20^{\circ} \mathrm{C}$ and $24^{\circ} \mathrm{C}$, Saccharomyces cerevisiae Bordeaux produced more acetaldehyde, acetone and 2-butanone compared to 8-11. At $28^{\circ} \mathrm{C}, 8-11$ strain produced more acetaldehyde and 2-butanone, $33.3 \%$ and $15 \%$ respectively, and $30 \%$ less acetone than Bordeaux.

The total aldehydes content in the experimental samples did not affect adversely their aromatic and taste qualities.

\section{REFERENCES}

Bambalov, G. (1981). Microbiology of wine production. Plovdiv: Publ. House Hristo G. Danov, 248 p.

Bueno, M., Marrufo-Curtido, A., Carrascon, V., Fernandez-Zurbano, P., Escudero, A. \& Ferreira, V. (2018). Formation and accumulation of acetaldehyde and strecker aldehydes during red wine oxidation. Frontiers in Chemistry, 6, 1 19. https://doi.org/10.3389/fchem.2018.00020

Byrne, S. \& Howell G. (2017). Acetaldehyde - how to limit its formation during fermentation. https://www.vintessential.com.au/acetaldehyde-how-to-limit-itsformation-during-fermentation/

Chen, L. Z., Nguang, S. K. \& Chen, X. D. (2006). Modelling and optimization of biotechnological processes. Artificial Intelligence Approaches. Berlin: Springer, 15, 123 p. https://doi.org/10.1007/978-3-540-32493-5

Chobanova, D. (2012). Enology. Wine composition. Part I. Plovdiv: UFT Academic Publishing House, 169-183. (BG)

Ferreira, D. C., Nicalli, K. P., Souza-Silva, E. A., Manfroi, V., Zini, C. A. \& Welke, J. E. (2018). Carbonyl copmpounds in different stages of vinification and exposure risk assessment through Merlot wine consumption. Food Additives \& $\begin{array}{llll}\text { Contaminations, } & \text { part 2315-2331. }\end{array}$ https://doi.org/10.1080/19440049.2018.1539530

Filimon, F.V., Nechita, B., Bora, F. D., Nechita, A. \& Filimon, R. (2021) Analysis of volatile compounds in low alcoholic wines obtained by reverse osmosis of grape must. AAB Bioflux, 13(1), 1-7, http://www.aab.bioflux.com.ro

Frivik, S. \& Ebeler, S. (2003). Influence of Sulfur Dioxide on the Formation of Aldehydes in White Wine. American Journal of Enology and Viticulture, 54(1), 31-38.

Herzan, J., Prokes, K., Baron, M., Kumsta, M., Pavlousek, P. \& Sochor, J. (2020). Study of carbonyl compounds in white wine production. Food Science \& Nutrition, 8, 5850-5859. https://doi:10.1002/fsn3.1855.

Hrivňak, J., Repka, V. \& Fričova, J. (2004). Characterisation of wine aroma by sorption and desorption of the gas phase. Book of Abstracts of the XXVIII World Congress of Vine and Wine, Wien: 125.

Ivanov, T., Gerov, S., Yankov, A., Bambalov, G., Tonchev, T., Nachkov, D. \& Marinov, M. (1979). Practicum in Wine Technology. Plovdiv: Plovdiv: Publ. House Hristo G. Danov, 530 p. (BG)

Jackowetz, J. N., Li, E. \& Orduña, R. M. (2011). Sulphur dioxide content of wines: the role of winemaking and carbonyl compounds. Research Focus: Cornell Viticulture and Enology, 3, 1-7. (a)

Jackowetz, J. N., Dierschke, S. \& Orduña, R. M. (2011). Multifactorial analysis of acetaldehyde kinetics during alcoholic fermentation by Saccharomyces cerevisiae. Food Research International, 44, 310-316. (b) http://dx.doi.org/10.1016/j.foodres.2010.10.014

Kramer, F. (1961). Paper chromatography. Sofia: Publ. House Technique, 232 p (BG)

Kružlicova, D., Mocak, J., Hrivňak, J., Ďurčekova, T. \& Argay, M. (2006) Classification of Slovak varietal wines by capillary GC with solid-phase microextraction. Zbornik vedeckych prac, XVI medzinarodna konferencia Chromatograficke metody a zdravie človeka, Pieštany: ÚACH FCHPT STU, Bratislava, pp. L17_1-L17_5, 2006.

Lago, L. O., Nicolli, K. P., Marques, A. B., Zini, C. A. \& Welke, J. E. (2017) Influence of ripeness and maceration of the grapes on levels of furan and carbonyl compounds in wine - simultaneous quantitative determination and assessment of the exposure risk to these compounds. Food Chemistry, 230, 594 603. https://doi:10.1016/j.foodchem.2017.03.090

Lago, L. O. \& Welke, J. E. (2019). Carbonyl compounds in wine: factors related to presence and toxic effects. Ciência Rural, 49(8), e20190349. http://dx.doi.org/10.1590/0103-8478cr20190349

Li, E. \& Orduña, R. M. (2017). Acetaldehyde kinetics of enological yeast during alcoholic fermentation in grape must. Journal of Industrial Microbiology\&Biotechnology, 44, 229-236. https://doi.org/10.1007/s10295-016$\underline{1879-7}$

Licek, J., Baron, M. \& Sochor, J. (2020). Comparison of MCFA and other methods of terminating alcohol fermentation and their influence on the content of carbonyl compounds in wine. Molecules, 25(23), 5737. https://doi:10.3390/molecules25235737

Liu, P. T., Lu, L., Duan, C. Q. \& Yan, G. L. (2016). The contribution of indigenous non-Saccharomyces wine yeast to improved aromatic quality of Cabernet Sauvignon wines by spontaneous fermentation. LWT - Food Science and Technology, 71, 356-363. http://dx.doi.org/10.1016/j.lwt.2016.04.031

Mina, M. \& Tsaltas, D. (2017). Contribution of yeast in wine aroma and flafour. INTECH, 5, 117-134. http://dx.doi.org/10.5772/intechopen.70656

Nikoletti, M. C., Jain, L. C. \& Giordano, R. C. (2009). Computational intelligence techniques for bioprocess modelling, supervision and control. Berlin Springer, 218, 1-23. https://doi.org/10.1007/978-3-642-01888-6

Orduña, R. M. (2014). Acetaldehyde management during winemaking. https://www.lallemandwine.com/wp-content/uploads/2014/09/WE5-CHINA.pdf

Romano, P., Suzzi, G., Turbanti, L. \& Polsinelli, M. (1994). Acetaldehyde production in Saccharomyces cerevisiae wine yeast. FEMS Microbiology letters 118, 213-218. https://doi.org/10.1111/j.1574-6968.1994.tb06830.x

Rosca, I., Petrovici, A. R., Brebu, M., Stoica, I., Minea, B. \& Marangoci, N. (2016). An original method for producing acetaldehyde and diacetyl by yeast fermentation. Brazilian Journal of Microbiology, 47, 949-954. https://dx.doi.org/10.1016\%2Fj.bjm.2016.07.005

Roustan, J. L. \& Sablayrolles, J. M. (2002). Modification of the acetaldehyde concentration during alcoholic fermentation and effects on fermentation kinetics. Journal of Bioscience and Bioengineering, 93(4), 367-375. https://doi.org/10.1016/S1389-1723(02)80069-X

Swiegers, J., Bartowsky, E., Henschke, P. \& Pretorius, I. (2005). Yeast and Bacterial Modulation of Wine Aroma \& Flavour - Part 4. The Australian Journal of Grape and Wine Research, 11(2), 139-173. https://doi.org/10.1111/j.17550238.2005.tb00285.x

Tsvetanov, O. (2001). How to Taste Wine. Sofia: Gourmet Publ. House , 43-46 (BG)

Yankov, A. (1992). Winemaking Technology. Sofia: Zemizdat Publishing House, 355 p. (BG)

Yoncheva, T., Spasov, H. \& Kostov, G. (2019). The impact of the fermentation conditions on the ester producing capacity of different Saccharomyces cerevisiae strains and the organoleptic profile of Cabernet Sauvignon wines. Journal of Microbiology, Biotechnology and Food Science, 9(3), 562-566. https://doi.org/10.15414/jmbfs.2019/20.9.3.562-566. 